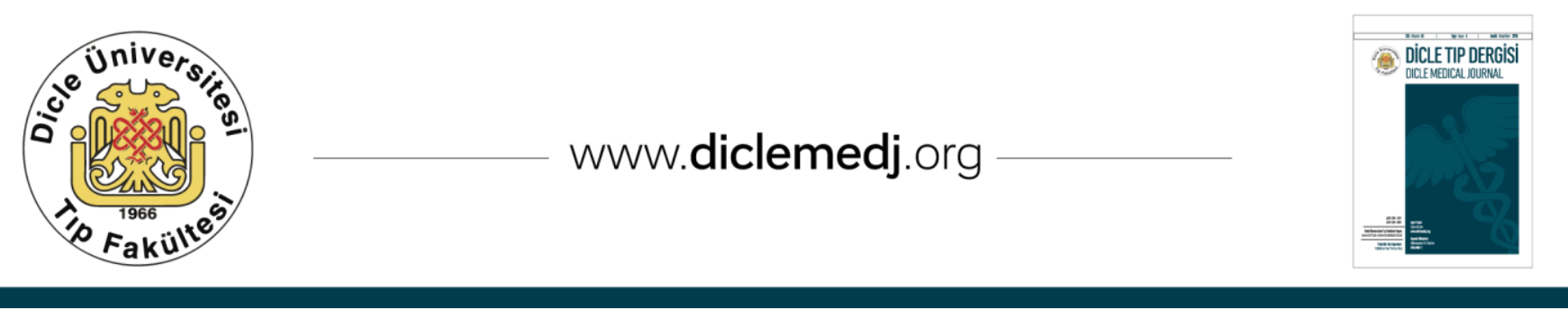

Özgün Araştırma / Original Article

\title{
Karpal Tünel Sendromu Hastalarında Elektrodiagnostik Evreleme ile Klinik Evre, Semptom Süresi ve Vücut Kitle İndeksi Arasındaki İlişkinin Değerlendirilmesi
}

\author{
Abdulkadir Tunç¹, Belma Doğan Güngen² \\ 1 Özel Adatıp Hastanesi, Nöroloji Kliniği, Sakarya, Türkiye \\ 2 Sakarya Üniversitesi, Eğitim ve Araştırma Hastanesi, Sakarya, Türkiye
}

Geliş: 30.07.2016 Revizyon: 11.04.2017 Kabul Tarihi: 12.04.2017

\section{Özet}

Amaç: Karpal tünel sendromu (KTS) tanısı klinik bulgular, fizik muayene ve elektromiyografi (EMG) ile konur. Vücut kitle indeksi (VKI) KTS gelişiminde önemli bir risk faktörüdür. Bu çalışmanın amacı KTS hastalarında demografik verilerin değerlendirilmesi, klinik evreleme, VKI ve semptom süresi ile elektrofizyolojik KTS grupları arasındaki ilişkinin incelenmesidir.

Yöntemler: Çalışmaya EMG laboratuvarımıza KTS ön tanısı ile gönderilen ve elektrofizyolojik olarak KTS tanısı alan 270 olgu alındı. Bu hastaların dosyaları retrospektif olarak incelendi. Tüm hastaların yaş, cinsiyet, dominant ve etkilenen el, boy, kilo ve semptom süreleri kaydedildi. Elektrofizyolojik değerlendirmeye göre hafif, orta ve ağır olarak gruplandırılan hastalar klinik evre, VKİ ve semptom süreleri ile karşılaştırıldı.

Bulgular: Çalışmaya alınan hastaların yaș ortalaması 44,35 $\pm 12,38$ yıl olup 237' si ( \%87,8) kadın idi. Tüm hastaların VKI ortalaması $27,85 \pm 2,93$ olup erkeklerde $26,68 \pm 2,74$, kadınlarda ise $28,02 \pm 2,92 \mathrm{~kg} / \mathrm{m} 2$ saptandı. $50(\% 18,3)$ hastada sadece sağ KTS, $32(\% 11,85)$ hastada sadece sol KTS, 188 hastada $(\% 69,62)$ ise bilateral KTS saptandı. EMG sonuçlarına göre sağ KTS ve sol KTS saptanan hastalarda elektrofizyolojik evreler ile semptom süresi, VKI ve klinik evre arasındaki ilişki istatistiksel olarak anlamlı bulundu. Bilateral KTS varlı̆̆ı ile klinik evre, semptom süresi ve VKI değerleri arasında da anlamlı ilişki saptandı $(\mathrm{p}<0,001)$.

Sonuç: Çalışmamızda uzun semptom süresi ve yüksek VKI, KTS varlığı ve şiddeti için birer risk faktörü olarak değerlendirilmiștir. Ayrıca klinik bulguların ağırlığı ile birlikte elektrofizyolojik bulguların benzer şekilde ilerlediğinin gözlenmesi, sinir iletim çalışmalarının KTS tanısında ve şiddetinin değerlendirilmesinde ek, bağımsız ve tarafsız kanıtlar sağladığı gerçeğini yinelemektedir.

Anahtar kelimeler: Karpal tünel sendromu, Evreleme, Vücut kitle indeksi

DOI: $10.5798 /$ dicletip.319741

Yazışma Adresi / Correspondence: Abdulkadir Tunç, Özel Adatıp Hastanesi, Sakarya, Türkiye e-mail: drkadirtunc@hotmail.com 


\title{
Evaluation of the Relationship Between Electrodiagnostic Staging and Clinical Stage, Symptom Duration and Body Mass Index in Carpal Tunnel Syndrome Patients
}

\begin{abstract}
Objectives: Carpal tunnel syndrome (CTS) is diagnosed with clinical symptoms, physical examination and electromyography (EMG). Body mass index (BMI) is an important risk factor in the development of CTS . The aim of this study was to evaluate the demographic data in CTS patients and to investigate the relationship between patients grouped with electrodiagnostic staging and BMI, symptom duration and clinical staging.

Methods: 270 cases who were sent to our EMG laboratory with initial diagnosis of CTS and electrophysiologically diagnosed with CTS were included in this study. Files of these patients were examined retrospectively. Age, gender, dominant and affected hand, height and weight, symptom durations of all patients were recorded. Patients grouped as mild, moderate and severe according to electrophysiological evaluation were compared in terms of clinical stage, BMI and symptom duration.

Results: The patients had an average age of $44.35 \pm 12.38$ years and 237 of them were female (87.8\%). The average BMI of patients was $27.85 \pm 2.93$ and detected as $26.68 \pm 2.74$ for men, $28.02 \pm 2.92 \mathrm{~kg} / \mathrm{m} 2$ for women. It was found that 50 of them (18.3\%) had only right CTS, 32 (11.85\%) had only left CTS and 188 had bilateral CTS (69.62\%). According to EMG results, the relationship between electrophysiological stages, symptom duration, BMI and clinical stage was statistically significant in patients with right CTS and left CTS. Significant correlations were also found between bilateral CTS presence and clinical stage, duration of symptoms and BMI ( $\mathrm{p}<0.001)$.

Conclusion: Long duration of symptoms and high BMI were considered as risk factors for the presence and severity of CTS in our study. In addition, the observation that electrophysiological findings have progressed in a similar way with the clinical findings reiterates the fact that nerve conduction studies provide additional, independent, and unbiased evidence for CTS and assessment of severity.
\end{abstract}

Keywords: Carpal tunnel syndrome, Staging, Body mass index

\section{GíRiş}

Karpal tünel sendromu (KTS) ellerde uyuşma, güçsüzlük ve ağrıya neden olan üst ekstremitelerin en slk görülen tuzak nöropatisidir ${ }^{1} .3$ ve 5 . dekatlarda ve kadınlarda daha sık görülmektedir². İyi tanınmasına karşın en sık nedenin idiopatik olması etyolojisinin hala net olmadığını göstermektedir ${ }^{3}$. Yüksek vücut kitle indeksi (VKI) KTS gelişiminde önemli bir risk faktörüdür. Bunun yanında yaș, cinsiyet, diabetes mellitus, tiroid hastalıkları, konnektif bağ dokusu hastalıkları, amiloidoz, akromegali ve tekrarlayan el hareketleri gibi durumlar da KTS için risk faktörleri arasında gösterilmiştir ${ }^{4,5}$.

KTS tanısı klinik bulgular, fizik muayene ve elektromiyografi (EMG) ile konulur. Klinik muayenede Tinel ve Phalen testi gibi provokatif testlerden sıklıkla yararlanılmaktadır 6 .
Subjektif klinik belirtilerle birlikte sinir iletimi çalışmaları (SİÇ), KTS vakalarında terapötik etkilerin tanı ve değerlendirilmesinde objektif ek modaliteler olarak kullanılmaktadır ${ }^{7}$. SİÇ, KTS tanısı için altın standart olarak düşünülmekte ve yüksek duyarlılık ve özgüllük ile tuzak nöropati şiddetinin değerlendirmesinde giderek daha fazla kullanılmaktadır ${ }^{8}$.

Provokatif testler ve fizik muayene, hastanın semptomlarının tetiklenmesi ve KTS' den şüphelenilmesi gerekip gerekmediğini belirlemek için basit ve düşük maliyetli yöntemler olmasına rağmen tanısal değerlerinin yetersizliği ve eğer hafif bir KTS söz konusuysa fizik muayenenin yetersiz prediktif değere sahip olabileceğini dikkate almak önemlidir. Literatürde, çeşitli provokatif testlerin pozitifliği ve KTS şiddeti arasında 
anlamlı ilişki saptanmadığı, bu nedenle bu testlere dayalı doğru diagnostik sonuçlara varmanın mümkün görünmediği bildirilmiştir ${ }^{8-}$ 10. Buna karşılık klinik evreleme yöntemleri ile elektrofizyolojik ölçümlerin hastalığın seviyesini belirlemede iyi bir korelasyon gösterdiği belirtilmiştir7. KTS evrelemesi üzerine literatürde çeşitli raporlar bulunmasına rağmen, spesifik bir yöntem oluşturulmamıştır ${ }^{3,7-9}$.

$\mathrm{Bu}$ çalışmada Padua ve ark. ${ }^{11}$ tarafından önerilen klinik evreleme yöntemi ile elektrofizyolojik KTS grupları arasındaki ilişki değerlendirildi. Bunun yanında obezite ve semptom süresi gibi risk faktörlerinin farklı elektrofizyolojik evreler ile ilişkisinin değerlendirilmesi amaçland.

\section{YÖNTEMLER}

Çalışmamıza Nisan 2015 ile Aralık 2015 tarihleri arasında EMG laboratuvarımıza KTS ön tanısı ile gönderilen ve elektrofizyolojik olarak KTS tanısı alan 17-77 yaş arası 270 olgu alındı. $\mathrm{Bu}$ olguların dosyaları retrospektif olarak incelendi. Çalışma için Sakarya Üniversitesi İlaç ve Tıbbi Cihaz Dıșı Araştırmalar Etik Kurulu' ndan onay alındı. Hastaların yaș, cinsiyet, dominant ve etkilenen el, boy, kilo ve semptom süreleri kaydedildi. Boy ve kilo ölçümleri değerlendirilerek $\mathrm{kg} / \mathrm{m}^{2}$ cinsinden VKİ hesapland.

Tüm hastalar semptomatik olup bir veya her iki elde en az gece ve/veya gündüz uyuşma ve/veya parestezi yakınmasına sahipti. İğne EMG çalışması gerektiren ve elektrodiagnostik olarak radikülopati/pleksopati bulguları olanlar, karpal tünel sendromu nedenli opere olanlar, gebelik, tiroid hastalıkları, amiloidoz, bağ dokusu hastalıkları ve üst ekstremiteye travma öyküsü olan hastalar çalışmaya dahil edilmedi.

Klinik bulgular Italyan KTS çalışma grubunun modifiye kriterlerine göre değerlendirildi ${ }^{11}$. Asemptomatik grup KTS evre 0 kabul edildi.
Evre 0-2 arası hafif, evre 3-5 ise ağır olarak gruplandı (Tablo 1).

Tablo 1. Karpal tünel sendromu' nda klinik evreleme

\begin{tabular}{lll}
\hline & Evre & Öykü ve objektif bulgular \\
\hline Asemptomatik & 0 & Asemptomatik \\
\hline Hafif & 1 & $\begin{array}{l}\text { Nokturnal parestezi } \\
\text { Nokturnal ve diürnal parestezi }\end{array}$ \\
\hline \multirow{2}{*}{ Ağır } & 2 & $\begin{array}{l}\text { Duysal kayıp } \\
\text { Medyan sinir innervasyonlu } \\
\text { kaslarda atrofi ve/veya } \\
\text { güçsüzlük } \\
\text { Medyan sinir innervasyonlu } \\
\text { tenar kaslarda paralizi }\end{array}$ \\
\hline
\end{tabular}

Çalışmada Nihon Kohden MEB-9400K (Nihon Kohden, Korp, Tokyo, Japonya, 2011) sistemi kullanıldı. EMG laboratuvarımızda filtre ayarı motor iletim çalışmaları için $20 \mathrm{~Hz}$ ile $10 \mathrm{kHz}$ arasında, stimülasyon sıklığı $1 \mathrm{~Hz}$ ve stimülasyon süresi 0,2 msn; duyu iletim çalışmaları için filtre ayarı $20 \mathrm{~Hz}$ ile $2 \mathrm{kHz}$ arasında, stimülasyon sıklığı $1 \mathrm{~Hz}$ ve stimülasyon süresi 0,2 msn olarak ayarlanmıștır. Rutin EMG incelemelerinde olduğu gibi prosedür boyunca oda sicaklığ ortalama 25 derece ve deri sıcaklığı $31-34^{\circ} \mathrm{C}$ arasında tutulmuştur. Elektrofizyolojik incelemelerimizde Amerikan Elektrodiagnostik Tıp Derneği önerileri dikkate alınmaktadır ${ }^{12}$.

Rutin EMG incelemelerinde olduğu gibi çalışma boyunca üst ekstremite sinir iletim çalıșmaları, bir sabit akım uyarıcısı ve yüzey elektrod kaydı ile supramaksimal perkütan stimülasyon standart teknikler kullanilarak gerçekleştirilmiştir. Median ve ulnar duyu iletimleri sırasıyla 2. ve 5. parmaklara kayıt elektrodları, el bileğine uyarıcı elektrod yerleştirerek antidromik olarak ölçülmüş, ayrica 4. parmaktan medyan-ulnar tepe latansı kaydı yapılmıştır. Median sinir motor iletim çalışmasında abduktor pollisis brevisten, ulnar sinir motor yanıt için abduktor digiti minimi kasından kayıt alınmış, distal latans, amplitüd ve sinir iletim hızları hesaplanmıştır. 
Tüm olgularda her iki el çalışılmış olup elektrofizyolojik olarak hastalar aşağıdaki kriterlere göre sınıflandırılmıştır ${ }^{13}$.

Hafif KTS: Median duysal yanıt distal latansı ile ulnar duysal yanit distal latansı arasındaki farkın > 1 msn olması veya 4 . parmak kayıtlı medyan-ulnar sinir tepe latansları arasındaki farkın $>0.5$ msn olması

Orta KTS: Yukarıdakilere ek olarak median motor sinirin distal latansının uzaması ( $>4.0$ msn)

Ağır KTS: Sıklıkla duysal potansiyel amplitüd düşüklüğü/yokluğu ve motor yanıt amplitüdünün düşmesi $(<5.0 \mathrm{mV})$ veya latansının gecikmesi (> $5.5 \mathrm{msn}$ ).

İstatistiksel Analizler

$\mathrm{Bu}$ çalışmadaki verilerin analizinde SPSS Statistics 21 kullanıldı. Verilerin normal dağılıma uyup uymadığına bakıldı. Bağımsız iki grubun sürekli verilerinin karşılaştırılmasında normal dağılıma uygunluk sağlanıyorsa t testi uymuyorsa mann whitney $\mathrm{u}$ testi kullanıldı. Sayım ile belirlenen veriler gruplandı ve bu grupların karşılaștırılmasında ki-kare testi kullanıldı. Sürekli değişkenler ile kategorize gruplar arası ilişkilerin karşılaştırılmasında kategori sayısı 3 ve üzeri ise ve sürekli değişken her grupta normal dağllıma uyuyorsa anova, normal dağılıma uymuyorsa kruskal wallis testi kullanıldı. $\mathrm{P}<0,05$ anlamlı kabul edildi.

\section{BULGULAR}

Bu çalışmaya EMG laboratuvarımızın 9 aylık kayıtları retrospektif incelenerek toplam 270 hasta dahil edildi. Hastaların yaş ortalaması $44,35 \pm 12,38$ yll olup 237' si $(\% 87,8)$ kadın idi. Hastaların 222' si $(\% 82,2)$ sağ el dominant iken $48^{\prime}$ i $(\% 17,8)$ sol el dominant idi. Tüm hastaların VKI ortalaması $27,85 \pm 2,93$ olup erkeklerde $26,68 \pm 2,74$, kadınlarda ise $28,02 \pm 2,92 \mathrm{~kg} / \mathrm{m}^{2}$ saptandi. Tek taraflı KTS varlığında VKI ortalaması $25,13 \pm 3,05$ iken bilateral KTS varlığında VKI ortalaması $28,17 \pm 2,82 \mathrm{~kg} / \mathrm{m}^{2}$ idi.

$50(\% 18,3)$ hastada sadece sağ KTS, 32 $(\% 11,85)$ hastada sadece sol KTS, 188' inde $(\% 69,62)$ ise bilateral KTS saptandı (Tablo 2). KTS saptanan hastaların elektrofizyolojik olarak evrelere göre dağılımı tablo $3^{\prime}$ te sunulmuştur.

Tablo 2. Karpal tünel sendromu hastalarının demografik ve klinik özellikleri

\begin{tabular}{ll}
\hline $\mathrm{n}: 270$ & $\mathrm{n}(\%)$ \\
\hline Cinsiyet (Erkek/Kadın) & $33(\% 12,2) / 237(\% 87,8)$ \\
El dominansı (Să̆/Sol) & $222(\% 82,6) / 48(\% 17,8)$ \\
KTS varlığı Să̆ & $50(\% 18,3)$ \\
Sol & $32(\% 11,8)$ \\
Bilateral & $188(\% 69,62)$ \\
\hline & Kadın Erkek Toplam \\
\hline Yaş* & $44.25 \pm 12.0045 .09 \pm 15.0244 .35 \pm 12.38$ \\
VKI ortalaması $\left(\mathrm{kg} / \mathrm{m}^{2}\right)^{*}$ & $28.02 \pm 2.9226 .68 \pm 2.7427 .85 \pm 2.93$ \\
Semptom süresi (ay)* & $53.02 \pm 45.5945 .20 \pm 41.5752 .02 \pm 45.11$ \\
\hline KTS: Karpal tünel sendromu, VKI: Vücut kitle indeksi \\
* ortalama \pm standart sapma
\end{tabular}

Tablo 3. Karpal tünel sendromu hastalarının elektrofizyolojik evrelere göre dağılımı

\begin{tabular}{lll}
\hline KTS Evresi & Sağ KTS n(\%) & Sol KTS n(\%) \\
\hline Hafif Evre Erkek & $6(\% 26,1)$ & $10(\% 45,5)$ \\
Kadın & $78(\% 36,2)$ & $80(\% 40,4)$ \\
Toplam & $84(\% 35,3)$ & $90(\% 33,3)$ \\
Orta Evre Erkek & $13(\% 56,5)$ & $11(\% 50,0)$ \\
Kadın & $93(\% 43,3)$ & $74(\% 37,4)$ \\
Toplam & $106(\% 44,5)$ & $85(\% 40,9)$ \\
İleri Evre Erkek & $4(\% 17,4)$ & $1(\% 4,5)$ \\
Kadın & $44(\% 20,5)$ & $44(\% 22,2)$ \\
Toplam & $48(\% 20,1)$ & $45(\% 20,5)$ \\
\hline
\end{tabular}

KTS: Karpal tünel sendromu

Elektrofizyolojik KTS evreleri semptom süreleri ile karşılaştırıldığında aralarındaki ilişki istatistiksel olarak anlaml bulunmuştur $(\mathrm{P}<0,001)$ (Tablo 4). Bilateral KTS hastaları sırasiyla să ve sol toplam KTS ile karşılaştırıldığında da daha uzun semptom süreleri olduğu saptandı. Sağ KTS hastalarında ortalama semptom süresi $34.8 \pm 29.5$ ay ve sol KTS hastalarında ortalama semptom süresi 
$31.6 \pm 20.3$ ay iken, bilateral KTS hastalarında semptom süresi ortalaması $59.5 \pm 48.6$ ay olarak saptandl.

Tablo 4. Karpal tünel sendromunda elektrofizyolojik evre ile semptom süresi ilișkisinin değerlendirilmesi

\begin{tabular}{lllll}
\hline \multirow{2}{*}{ Lateralizasyon } & $\begin{array}{l}\text { Elektrofizyolojik } \\
\text { evre }\end{array}$ & $\mathrm{n}$ & $\begin{array}{l}\text { Semtpom } \\
\text { süresi (ay) }\end{array}$ & $\mathrm{P}:$ \\
\hline \multirow{3}{*}{ Sağ KTS } & Hafif & 84 & $34.84 \pm 15.78$ & \\
& Orta & 106 & $52.64 \pm 19.58$ & $\mathrm{P}<0.001$ \\
& Ağır & 48 & $95.50 \pm 22.15$ & \\
\hline \multirow{3}{*}{ Sol KTS } & Hafif & 90 & $34.86 \pm 12.41$ & \\
& Orta & 85 & $61.34 \pm 17.87$ & $\mathrm{P}<0.001$ \\
& Ağır & 45 & $83.80 \pm 26.44$ & \\
\hline Bilateral & Var & 188 & $59.59 \pm 18.61$ & $\mathrm{P}<0.001$ \\
KTS & Yok & 82 & $34.82 \pm 9.53$ & \\
\hline
\end{tabular}

KTS: Karpal tünel sendromu

$\mathrm{p}<0.05$

Hem sağ, hem sol KTS saptanan hastalarda KTS evresi ile VKI değerleri arasında anlamlı ilişki saptandl. $(\mathrm{P}<0,001, \mathrm{P}=0,046)$. Bilateral KTS varlığı ile VKI değerleri arasında da anlamlı ilişki saptandı $(\mathrm{P}=0,007)$ (Tablo 5).

Tablo 5. Karpal tünel sendromunda farklı elektrofizyolojik evreler ile VKI ilișkisi

\begin{tabular}{lllll}
\hline \multirow{2}{*}{ Lateralizasyon } & $\begin{array}{l}\text { Elektrofizyolojik } \\
\text { evre }\end{array}$ & $\mathrm{n}$ & $\mathrm{VKI}(\mathrm{kg} / \mathrm{m} 2)$ & $\mathrm{P}:$ \\
\hline \multirow{3}{*}{ Sağ KTS } & Hafif & 84 & $26.80 \pm 2.73$ & \\
& Orta & 106 & $28.32 \pm 2.72$ & $\mathrm{p}<0.001$ \\
& Ağır & 48 & $29.16 \pm 3.05$ & \\
\hline \multirow{3}{*}{ Sol KTS } & Hafif & 90 & $27.46 \pm 2.75$ & $\mathrm{p}: 0.046$ \\
& Orta & 85 & $28.09 \pm 2.63$ & \\
& Ağır & 45 & $28.92 \pm 3.24$ & \\
\hline Bilateral & Var & 188 & $28.17 \pm 2.82$ & \multirow{2}{*}{ KTS } \\
\hline
\end{tabular}

KTS: Karpal tünel sendromu, VKI: Vücut kitle indeksi $\mathrm{p}<0.05$

Klinik evre ile sağ ve sol KTS grupları karşılaştırıldığında aralarındaki ilişki istatistiksel olarak anlamlı bulundu $(\mathrm{P}<0,001)$ (Tablo 6).

\section{TARTIŞMA}

Bu çalışmada KTS hastalarında elektrofizyolojik olarak belirlenen evrelerin obezite, semptom süresi ve klinik evreleme ile ilişkisi değerlendirildi. EMG sonuçlarına göre sağ KTS ve sol KTS saptanan hastalarda elektrofizyolojik evreler ile semptom süresi, VKI ve klinik evre arasındaki ilișki istatistiksel olarak anlamlı bulundu. Bilateral KTS varlığı ile klinik evre, semptom süresi ve VKI değerleri arasında da anlamlı ilişki saptandı.

KTS tanısı için literatürde çeşitli yöntemler öne sürülmekle birlikte sıklıkla klinik semptomlar, fizik muayene ve elektrofizyolojik çalışmaların birlikte değerlendirilmesi ile tanı konulmaktadır ${ }^{14}$. KTS' de klinik bulguların nörofizyolojik bulgularla iyi ilişkili olup olmadığı uzun zamandır tartışılmaktadır. KTS şiddetinin değerlendirilmesi, prognozu ve tedavi önlemlerini tanımlamak için önemli bir adımdır.

Tablo 6. Karpal tünel sendromunda klinik evre ile elektrofizyolojik grupların karşılaștırılması

\begin{tabular}{llcllc}
\hline \multirow{2}{*}{ Elektrofizyolojik evre } & Asemptomatik & Hafif & Ağır & $\mathrm{p}:$ \\
\hline \multirow{4}{*}{ Sağ KTS } & Yok & 2 & 30 & 0 & \\
& Hafif & 3 & 79 & 2 & $\mathrm{p}<0.001$ \\
& Orta & 1 & 100 & 5 & \\
& Ağır & 0 & 14 & 34 & \\
\multirow{3}{*}{ Sol KTS } & Yok & 1 & 46 & 3 & \\
& Hafif & 4 & 85 & 1 & $\mathrm{p}<0.001$ \\
& Orta & 0 & 74 & 11 & \\
& Ağır & 1 & 18 & 26 & \\
\hline
\end{tabular}

KTS: Karpal tünel sendromu $\mathrm{p}<0.05$

Her ne kadar KTS şiddetinin belirlenmesinde çok sayıda sınıflama önerilmiş ve elektrofizyolojik evreleme ile klinik semptomlarm şiddeti arasında iyi bir korelasyon olduğu gösterilmiş olsa da, spesifik bir metod gösterilememiştir ${ }^{15,16}$. Çalışmamızda İtalyan KTS çalışma grubunun modifiye kriterleri11 kullanılarak farklı klinik semptom ve bulgulara sahip hastalar arasındaki nörofizyolojik farklılıkları ilişkilendirmek amacıyla hastalar klinik olarak asemptomatik, hafif ve ağır olarak sınıflandırıldı. Si̇ç' nda sağ, sol ve bilateral KTS saptadığımı hastalarda elektrofizyolojik gruplar ile klinik evreler arasındaki ilişki anlamlı bulundu. Literatürde İtalyan KTS çalışma grubu ve Bland tarafından yapılan çalışmalarda klinik evreleme ile elektrofizyolojik evreleme arasinda anlamlı korelasyon saptanmıştır ${ }^{11,17}$. Leventoğlu ve 
ark.' nın yapmış olduğu bir çalışmada ise, 226 KTS olgusu klinik ve elektrofizyolojik evreleme açısından karş̧laştırılmış, aralarında anlamlı korelasyon saptanmış ancak klinik olarak ılımlı ve ağır olarak etkilenmiş ellerde elektrofizyolojik evrelerin ağırlığı bakımından anlamlı farklılık izlenmemiștir ${ }^{18}$.

SíÇ, medyan sinirdeki anlamlı sıkışma iskemik demiyelinizasyona neden olduktan sonra anormal hale gelme eğilimindedir. $\mathrm{Bu}$, önce fleksör retinakulumun derinine doğru ilerleyen hızlı iletken liflerde meydana gelir ${ }^{1-3}$. Böylece median sinirin yüzeyel duyusal dalını ölçen rutin SİÇ patolojiyi alamayabilir. Diğer taraftan kullanılan klinik evreleme sistemlerinin farklılığı ve elektrofizyolojik olarak da değişebilen evreleme yöntemlerinin söz konusu tutarsızlığa neden olmuş olabileceği düşüncesindeyiz.

Literatürde obezitenin KTS için bağımsız bir risk faktörü olduğu ve olguların \%70' inin obez olduğu bildirilmiştir ${ }^{19,20}$. VKİ değeri yüksek olan kişilerde geniş sinir gövdeleri etrafında destek doku olarak bulunan yağ dokusu miktarının arttığı ve bu durumun karpal kanalda darlığa yol açarak tuzak nöropati gelişim riskini arttırdığı saptanmıştır ${ }^{21,22}$. VKİ ile KTS arasındaki bu ilişkinin diğer bir nedenine karpal kanaldaki artmış yağ depolanması veya karpal tünel içerisindeki artmış hidrostatik basıncın neden olduğunu düşündüren veriler bildirilmiştir ${ }^{23}$. Çalışmamızda VKI değerleri ile elektrofizyoloik KTS evreleri arasında anlamlı ilişki saptanmıştır. 720 hastayı içeren retrospektif bir çalışmada, KTS' si olan hastalarda VKI' nin KTS' si olmayanlara göre anlamlı derecede yüksek olduğu bulunmuştur ${ }^{24}$. Hlebs ve ark. ${ }^{25}$, regresyon analizini kullanarak KTS için bağımsız risk faktörlerini araştırmış ve el bileği indeksi, VKI ve el uzunluğunun vücut yüksekliğine oranını KTS için bağımsız risk faktörleri olarak belirlemiştir. Diğer taraftan obezite oranlarına bakıldığında, çalışmamızda tüm hastalardaki VKİ ortalaması $27,85 \pm 2,93$ $\mathrm{kg} / \mathrm{m}^{2}$ iken TURDEP' te Türk nüfusun \%57' si > $24,9 \mathrm{~kg} / \mathrm{m}^{2}$ saptanmıștır ${ }^{26}$. Çalışmamızın obezite oranları önceki çalışmalarda tanımlanan oranlardan daha yüksek izlenmiștir ${ }^{24-26}$.

Hastalarımızın semptom süreleri oldukça değişken olup $(4,34 \pm 3,76$ yil $)$ şikayetlerin süresi ile elektrofizyolojik KTS evreleri arasındaki ilişki istatistiksel olarak anlamlı bulundu. Literatürdeki veriler sınırlı olmakla birlikte ${ }^{27}$ çalıșmamız, semptom süresi ile KTS şiddeti arasında belirgin ilişkinin saptandığı ve bu durumun yaşla birlikte belirgin bir risk faktörü olarak değerlendirildiği benzer bir çalışma ile uyumlu bulunmuştur ${ }^{28}$.

Çalışmamızın kısıtlılıkları arasında klinik evrelemede daha kompleks sistemlerin kullanılamamıș olması, örneğin semptom ölçekleri veya tinel-phalen testlerinin eklenmemiş olması, çalışmanın retrospektif olması ve hasta sayısının azlı̆̆ı yer almaktadır.

Sonuç olarak bu çalışmada, uzun semptom süresi ve yüksek VKI KTS varlığı ve şiddeti için birer risk faktörü olarak değerlendirilmiștir. Ayrıca klinik bulguların ağırlığı ile birlikte elektrofizyolojik bulguların benzer şekilde ilerlediğinin gözlenmesi, SİÇ’ nin KTS tanısında ve şiddetinin değerlendirilmesinde ek, bağımsız ve tarafsız kanıtlar sağladığı gerçeğini yinelemektedir.

Çıkar Çatışması Beyanı: Yazarlar çıkar çatışması olmadığını bildirmişlerdir.

Finansal Destek: Bu çalışma her hangi bir fon tarafından desteklenmemiştir.

Declaration of Conflicting Interests: The authors declare that they have no conflict of interest.

Financial Disclosure: No financial support was received. 


\section{KAYNAKLAR}

1. Katz JN, Simmons BP. Carpal tunnel syndrome. N Eng J Med 2002; 346:1807-12.

2. D'Arcy CA, McGee S. The rational clinical examination. Does this patient have carpal tunnel syndrome? JAMA 2000; 283:3110-7.

3. Uchiyama S, Itsubo T, Nakamura K, Kato H, Yasutomi T, Momose T. Current concepts of carpal tunnel syndrome. Pathophysiology, treatment and evaluation. J Orthop Sci 2010; 15:1-13.

4. Karpitskaya Y, Novak CB, Mackinnon SE. Prevalence of smoking, obesity, diabetes mellitus, and thyroid disease in patients with carpal tunnel syndrome. Ann Plast Surg 2002; 48:269-73.

5. Bland JD. Carpal tunnel syndrome. Curr Opin Neurol 2005; 18:581-5.

6. Alemdar M. Carpal Tunnel syndrome: Anatomy, symptoms, diagnostic tools and treatment: Review. Turkiye Klinikleri J Neur 2009; 4(1):19-32.,

7. Ogura T, Akiyo N, Kubo T, et al. The relationship between nerve conduction study and clinical grading of carpaltunnelsyndrome. J Orthop SurgRes 2003;11(2): 190-3.

8. Srikanteswara PK, Cheluvaiah JD, Agadi JB, Nagaraj K. The relationship between nerve conduction study and clinical grading of carpal tunnel syndrome. BMJ Open 2016; 6(9): e012053.

9. Werner RA, Andary M. Electrodiagnostic evaluation of carpal tunnel syndrome. Muscle Nerve 2011; 44(4): 597-607.

10. American Academy of Orthopaedic Surgeons. Clinical practice guideline on the treatment of carpal tunnel syndrome. Muscle Nerve 2011; 44: 597-607.

11. Padua L, Padua R, Lo Monaco M, Romanini E, Tonali P. For the Italian CTS Study Group. Multiperspective assessment of carpal tunnel syndrome. A multicenter study. Neurology 1999; 53: 1654-9.

12. Jablecki CK, Andary MT, So YT, Wilkins DE, Williams FH. Literature review of the usefulness of nerve conduction studies and electromyography for the evaluation of patients with carpal tunnel syndrome. AAEM Quality Assurance Committee. Muscle Nerve 1993; 16: 1392-414.

13. Stevens JC. AAEM minimonograph \#26: The electrodiagnosis of carpal tunnel syndrome. American Association of Electrodiagnostic Medicine. Muscle Nerve 1997; 20: 1477-86.

14. Chan L, Turner JA, Comstock BA, et al. The relationship between electrodiagnostic findings and patient symptoms and function in carpal tunnel syndrome. Arch Phys Med Rehabil 2007; 88: 19-24.
15. Kasundra GM, Sood I, Bhargava AN, et al. Carpal tunnel syndrome: Analyzing efficacy and utility of clinical tests and various diagnostic modalities. J Neurosci Rural Pract 2015; 6:504-10.

16. Ali Z, Khan A, Shah SMA, Zafar A. Clinical and electrodiagnostic quantification of the severity of carpal tunnel syndrome. Ann Pak Inst Med Sci 2012; 8(4): 207-12.

17. Bland JD. Do nerve conduction studies predict the outcome of carpal tunnel decompression? Muscle Nerve 2001; 24:935-40.

18. Leventoglu A, Kuruoglu R. Do electrophysiological findings differ according to the clinical severity of carpal tunnel syndrome? J Neurol Sci 2006; 23:272-8.

19. Moghtaderi A, Izadi S, Sharafadinzadeh N. An evaluation of gender, body mass index, wrist circumference and wrist ratio as independent risk factors for carpal tunnel syndrome. Acta Neurol Scand 2005; 112:375-9.

20. Şahin N, Albayrak İ, Uğurlu H. Obez hastalarda karpal tünel sendromunun şiddeti ve vücut kitle indeks değerleri arasındaki ilişki. TUBAV Bilim Dergisi 2009; 2(4): 484-8.

21. Sungpet A, Suphachatwong C, Kawinwonggowit V. The relationship between body mass index and the number of sides of carpal tunnel syndrome. J Med Assoc Thai 1999; 82:182-5.

22. Kouyoumdjian JA, Zanetta DMT, Morita MP. Evaluation of age, body mass index, and wrist index as risk factors for carpal tunnel syndrome severity. Muscle Nerve 2002; 25:93-7.

23. Werner RA, Albers JW, Franzblau A, Armstrong TJ. The relationship between body mass index and the diagnosis of carpal tunnel syndrome. Muscle Nerve 1994;17:632-6.

24. Kurt S, Karaer H, Kaplan Y, Etikan İ. The relationship between carpal tunnel syndrome and body mass index, ageandgender. Turk J Phys Med Rehab 2006; 52:154-7.

25. Hlebs S, Majhenic K, Vidmar G. Body mass index and anthropometric characteristics of the hand as risk factors for carpal tunnel syndrome. Coll Antropol 2014; 38: 219-26.

26. Satman I, Yilmaz T, Sengül A, et al. Population-based study of diabetes and risk characteristics in Turkey: results of the turkish diabetes epidemiology study (TURDEP) Diabetes Care 2002; 25: 1551-6.

27. Kouyoumdjian JA. Duration of symptomatology and median segmental sensory latency in 993 carpal tunnel syndrome hands (668 cases). Arq Neuropsiquiatr 1999; 57(2A): 198-201. 
TunçA., Doğan Güngen B.

28. Kouyoumdjian JA. Carpal tunnel syndrome: age, nerve conduction severity and duration of symptomatology. Arq. NeuroPsiquiatr 1999; 57(2B): 382-6. 